\title{
The correlation between rock pool size and species diversity
}

\begin{abstract}
The relationship rock pool area holds; when compared with the species diversity of algae, was investigated on a rocky shore at Celmyn bay during mid-October 2014. Small experimental procedures were specifically designed to test whether the size of the rock pools recorded, made an impact on the total species diversity that occurred on the midshore at low tide, to test the hypothesis that seaweed diversity; in large mid-shore level rock pools, would be greater than that of smaller mid-shore level rock pools. Although during testing an apparent increase in diversity was noted in relation to increasing rock pool size, no significant difference was found between the two variables and the stated hypothesis of the investigation was shown by the results to be rejected in favour of the null hypothesis. Therefore emphasising that there may be outstanding factors which this study has not addressed, which may have an effect on the species diversity of rock pools on a rocky shore.
\end{abstract}

Volume 2 Issue 4 - 2015

\author{
Jennah Williams \\ Department of Marine Biology, Bangor University, USA
}

Correspondence: Jennah Williams, Department of Marine Biology, Bangor University, 442I Mariannes Ridge Rd Charlotte NC 28273, USA, Tel 7046I21880,

Email jennahvwilliams@hotmail.co.uk

Received: May 14, 2015 | Published: September 01, 2015

Keywords: Species diversity, Rock pool, Algae, Different species, Corallina officinalis

\section{Introduction}

The mid-shore zone of a rocky shore is home to many different species of algae. Some species have adapted to living in conditions of high salinity (Ulva sppand Porphyra umbilicalis), some have developed adaptations to survive in shallower waters (Chondrus crispus and Corallina officinalis) and some have adapted to thrive in exposed weather conditions (Laminaria digitata and Ascophyllum nodosum.)Research into the reasons seaweed populations are so diverse is numerous; with light intensity, temperature ${ }^{1,2}$ and seasonal change $^{3}$ offering explanations as to the distribution of different species. The Jacobucci et al. ${ }^{3}$ study highlights that certain seasons (winter in January and autumn in April) produce higher morphological characteristics of algae in shallower waters, furthermore the study showed that, in general, "fronds tended to be shorter, heavier and more ramified in shallower areas". One of the final conclusions of the study sights depth as a major factor in the adaptation of the brown algae S. cymosum.

Rock pool height in relation to sea level has also been investigated, showing correlations between species diversity of algae, ${ }^{4}$ however Hayes $^{4}$ demonstrates that the number of algal species in rock pools is negatively correlated with the height of the rock pools above sea level. Conditions in the higher shore area present increasingly harsher environments for marine algae to thrive in. Shallower rock pools in the higher shore area are more inclined to evaporate quickly, therefore increasing the salinity of the remaining rock pool water. ${ }^{5}$ On the other hand, some rock pools formed on the upper-shore are frequently formed by rain water; therefore increasing the fresh water content percentage, this presents a challenge to the algae; to adapt to survive. Longer tidal absence also makes higher shore marine organisms an easier target for marine birds, reducing the numbers of algal species in such areas.

The mid-shore zone is also a particularly harsh place for organisms to survive. High wave action can dislodge marine organisms in this zone and transport them either lower down or higher up the shore, which could in effect place the organism in a less adaptable habitat for that particular creature and therefore cause reproductive/feeding or migratory problems. However species living on the mid shore have an added benefit of not being dried out too severely even in high temperatures, compared to species situated on the high shore, due to the incoming tides submerging them again ever few hours. ${ }^{6}$ This is a huge advantage for mid shore species and is a possible reason as to why the mid shore is such a highly diverse area of any shore for algal species, when compared with other zones. This investigation looked to assess the relationship between rock pool area and species diversity, on the mid-intertidal zone of a rocky shore, taking all these factors in to account to finalise whether rock pool area is the only relevant factor of total species diversity on rocky shores around the coast of the British Isles.

\section{Case}

The experiment took place at Celmyn bay on the 26th October 2011. The rock pools were monitored on the mid-shore only, as the lower shore rock pools showed only one or two species of seaweed and the upper-shore pools were all very small. The barrier of the mid-shore to upper-shore was calculated by the sudden increased number of barnacles showing where the mid-shore zone was and the separation between mid and lower shore was obvious as lower shore was under water at this time. Random sampling of 35 pools took place, measuring length, width and depth with a tape measure and metre ruler to find the overall area of the pool. An even number of large pools where measured compared with small pools, to make this experiment fair. The different species of algae were then identified, using an Identification card and recorded in a table. The pool sizes were also recorded in a table to compare the size of the pool to the diversity of species found there. Species diversity is defined as the number and abundance of species at one point at a defined period. ${ }^{7}$

\section{Results}

Following this experiment, the results obtained showed, that the larger rock pools had significantly higher species diversity when compared with the smaller rock pools. However, the species diversity failed to exceed 9 different species in one area, no matter how large the rock pool was. This perhaps emphasises that the location of the rock pool is a major factor in species diversity, as well as the size of the rock pool, as rock pools near the lower-mid shore showed a higher 
species variation then pools of the higher-mid shore of the same size, a point further investigated within the discussion of the results.

Figure 1 shows a weak, yet positive correlation between the increase in pool size and the increase in species diversity. However the greatest difference in species diversity is between the pool size of Ln7.00 and Ln11.00. Pool sizes of larger value than then Ln11.00 do not show a significant increase in the diversity of species, again suggesting that pool size is not the only factor effecting species population. Figure 1 also shows that the hypothesis has not been supported, as the $\mathrm{P}$ value is greater than $0.05(\mathrm{P}=0.136)$, therefore showing no significant difference between the two variables, resulting in the acceptance of the null hypothesis.

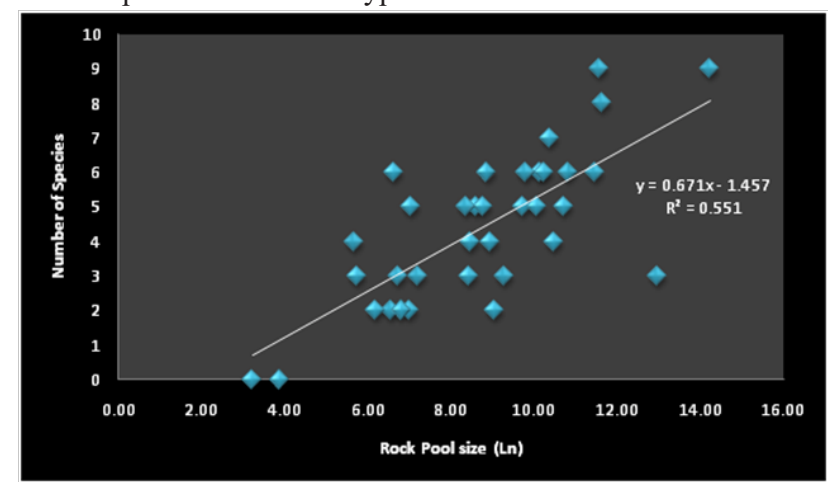

Figure I Figure I shows the Variation of algal species diversity with rock pool size.

Following the experiment the original result data had to be modified to portray an efficient figure, as the raw data collected was not appropriate when displayed in a graph form. The original data showed the surface area of 35 different sized rock pools (when measuring the length, width and depth to find the total surface area), evidently providing numbers of huge differences (e.g. -0.008 -890.87) this data was therefore inappropriate to be presented in a graph and had to be square rooted to make the results more similar, however as the results were still too different to be valid in a graph, the results were then logged $(\mathrm{Ln})$ so they were then on a scale that would be more comparable in a graph.

The R2 value portrays slight correlation, showing that there is some correlation however it is weak. The points recorded are not very close to the trend line, presenting a suggestion that the size of the rock pool is not the only factor affecting the results, if it was so, one would expect the R2 value to be approximately 9. The gradient of the trend line is calculated at 0.67 , emphasising a shallow increase of the species diversity of algae in comparison with the size of the rock pools. Figure 1 also shows that the trend line would be intercepted on the $\mathrm{X}$ axis at approximately at $\mathrm{Ln} 2$, hypothesising a possible complete decline in algal numbers below rock pool sizes of Ln2, this being said, due to the fact that the $\mathrm{R} 2$ value is 0.55 , there is a possibility of potential outliers; occurring above or below the trend line after interception. This highlights the fact that different factors need to be taken in to account before relying on data and that some findings should not necessarily be taken at face value. When the results had been collected and analysed, it was apparent that certain species were more abundant than others, regardless of the size of the rock pool, underlining again that there may be are other factors accountable for diversity of species, in conjunction with different pool sizes.

Figure 2 shows the most common species that occurred at the midshore zone of the rocky shore in the rock pools recorded Corallina officinalis, a small red algae, generally distributed across rocky shores all around the British Isles (that typically forms a turf in rock pool from the mid- tidal level to the sub-littoral fringe). In all cases it was the most frequently recorded species in the pools. Pools between Ln 8 and Ln 10 the highest number of recorded species, this could have been because of where on the mid-shore the pools were recorded for example lower-mid shore, or the fact that algae can thrive in this sized pool, again Corallina officinalis was the most frequently recorded species, however this species normally only flourishes on exposed shores, therefore if the experiment was done elsewhere, the results may differ. Another very common species on the rocky shore was Ulva spp. Rock pools which are subject to varying salinity and widely fluctuating temperatures are often characterised by this algae. However no species were recorded below Ln4; suggesting that rock pool size may, in fact, affect species diversity.

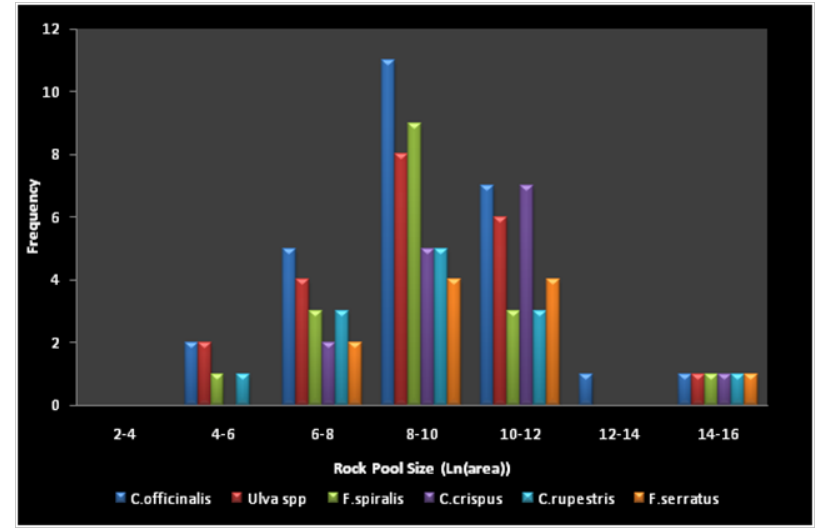

Figure 2 Shows the most common species of algae compared with rock pool size.

Figure 3 shows the species diversity compared to the depth of the pools recorded. The graph shows that; in the shallower pools, a small increase in depth can have a great increase in species recorded, showing the depths between $0 \mathrm{~cm}$ and $20 \mathrm{~cm}$ had the greatest species diversity change for the smallest depth increase. However, as the pools increase in depth, it appears that a greater difference in depth is needed to show any difference in species diversity. Therefore results show that depth does increase the species diversity, however only up to a certain point, in this instance; $50 \mathrm{~cm}$, at which point; the species variation stays the same and no new species are recorded.

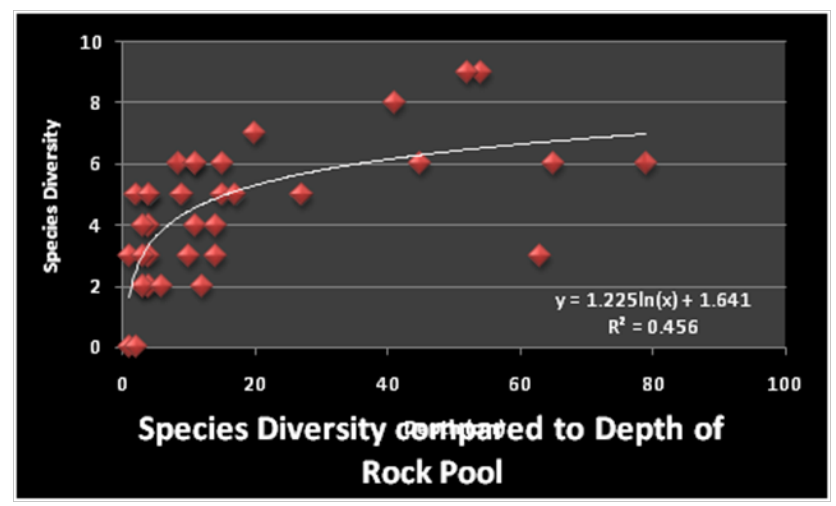

Figure 3 A graph showing the affect rock pool depth has on species diversity.

\section{Discussion}

The stated hypothesis of the investigation was shown by the results to be rejected in favour of the null hypothesis. This being said, rock pools varying between $20 \mathrm{~cm}$ and $50 \mathrm{~cm}$ in depth were shown 
to facilitate large variation in species this is shown in Figure 3. The greatest increase in species diversity occurred mostly with in small depth changes; this could be due to the slight increase in space, also the increase in light for the algae to photosynthesise more efficiently and reproduce more rapidly. However, after the depth of $50 \mathrm{~cm}$ the species diversity seemed to decrease rapidly to between 2 and 6 species. Following these findings it was apparent that the rock pools with a depth greater than $50 \mathrm{~cm}$ was predominantly inhabited by the kelp species Laminaria digitata. This pioneer species of the midlower rock pools dominated the deeper pools, obscuring any light from entering the depths of the pool with its meter long blades, thus making it near impossible for any other species to grow and survive in these deeper rock pools. Another possible reason for the decrease in species diversity in the deeper rock pools could be the slight increase in heat at the very bottom of the pool. On inspection of the pool, faint heat ripples where recorded and a noticeably higher temperature of the water was apparent. This was predicted to be a small under water hydrothermal vent; heating the bottom of the pool. The presence of such vents would have a significant increase on the temperature of the pool and make it an undesirable place for British Isle algae to thrive and grow. Therefore, taking this in to consideration, deeper rock pools would have a slight decrease in the species diversity compared with shallower pools around $20 \mathrm{~cm}-50 \mathrm{~cm}$ due to the increased pioneer species and the increased water temperature.

The repeated detection of Corallina officinalis in pools with areas between Ln 4 and Ln 16 may suggest that this is a highly adaptable species. Bussel et al. ${ }^{8}$ also showed findings of high populations of Corallina officinalis dominating rock pools at sites in the North Wales area. A possible explanation as to why Corallina officinalis is so abundant maybe attributable to the fact that it forms calcium carbonate deposits within the algal cells, which in turn strengthens the thallus. It is possible that the concentrated calcium carbonate makes the algae unpalatable to most rocky shore grazers, for example Littorina littorea andtherefore with no predators threatening its survival, the species is allowed to prosper without threat.'

Addressing the study's main hypothesis, the comparison of species diversity with rock pool area on the mid-intertidal zone of a rocky shore, showed a weak yet positive correlation. This being said the analysis of data showed that there was no significant difference between the two variables, as the $\mathrm{P}$ value was higher than 0.05 , resulting in the null hypothesis being accepted. The data shows that, at first, the slight increase of pool area did appear to make an impact on the amount of algal species found in the pools. However as Figure 1 shows, the trend then declines and species diversity does not exceed 9 different species within any one pool. The presence of 9 species in one rock pool is likely to suggest increased competition for food, light and space which could in turn be the reason why there is no greater species diversity than 9 species in any one pool. However it would not be unfathomable for future hypotheses' to predict the opposite of the study's findings, suggesting smaller rock pools, with high diversity of algae, would provide increased competition for light, food and space (due to the reduced pool area and increased population).

In conclusion this study has touched on the comparison between species diversity and rock pool size on the mid-intertidal zone of a rocky shore in the British Isles. However there are various limitations to this investigation. The investigation took place on only one rocky shore in one area of the British Isles coast, in only one zone of the shore. Therefore the results obtained are only significant to this one shore and thus so cannot be widely distributed as being generalizable for all shores in similar areas. Similarly, this investigation was only done in a time space of approximately 2 hours, of one month in only one season of the year. Therefore the results also cannot be justified as being generalised for the whole year on this shore. Another limitation of this investigation is that the number of predatory grazing organisms at the site was not taken in to account when counting the species of algae in the rock pools and as a result, the findings may not be representative of the true environment the study was conducted in, as a higher predatory species count would perhaps be the reason for lower species diversity, regardless of pool size.

To improve this study it may be beneficial to consider the time of year, the weather and the season as affecting factors. It is possible that certain species of algae may only be able to reproduce at certain times of the year (i.e. spring/summer when the investigation took place midOctober); it is therefore possible that this could have had an effect on the final results. ${ }^{10}$ Finally, the study may highlight an area of interest for other intertidal algae researchers; to further knowledge regarding the relationship between species diversity and total rock pool area.

\section{Acknowledgments}

None.

\section{Conflicts of interest}

None.

\section{References}

1. De Wreede RE. The phenology of three species of Sargassum (Sargassaceae, Phaeophyta) in Hawaii. Phycologia. 1976;15(2):175-183.

2. Glenn EP, Smith CM, Doty MS. Influence of antecedent water temperatures on standing crop of Sargassum spp.-dominated reef flat in Hawaii. Marine Biology. 1990;105(2):323-328.

3. Jacobucci GB, Guth AZ, Leite FPP. Influence of a narrow depth gradient and season on the morphology, phenology, and epibiosis of the brown alga Sargassum cymosum. Journal of the Marine Biological Association of the United Kingdom. 2010;91(4):761-770.

4. Hayes C. Vertical Distribution of Algal Species in Rock Pools in SouthEastern Australia. Cross-section. Volume III. 2007.

5. Damgaard RM, Davenport J. Salinity tolerance, salinity preference and temperature tolerance in the high-shore harpacticoid copepod Tigriopus brevicorni. Marine Biology. 1994;118(3):443-449.

6. Cartwright DE. Tides A Scientific History. Cambridge University Press. 1998;8(2):300-324.

7. Rosenzweig ML. Species diversity in space and time. Cambridge University Press, Cambridge, US. 1995.

8. Bussell JA, Lucas AN, Seed R. Patterns in the invertebrate assemblage associated with Corallina officinalis in tide pools. Journal of the Marine Biological Association of the United Kingdom. 2007;87(2):383-388.

9. Cases MR, Stortz CA, Cerezo AS. Structure of the 'corallinans'sulfated xylogalactans from Corallina officinalis.Int J Biol Macromol. 1994;16(2):93-97.

10. Lubchenco J. Heteromorphic Life Histories of Certain Marine Algae as Adaptations to Variations in Herbivory. Ecological Society of America. 1980;61(3):676-687. 